Original Article

\title{
Influences of remote exercise training for community-dwelling older adults in Japan during the COVID-19 pandemic
}

\author{
Kazuhiro Miyata, RPT, PhD ${ }^{1)^{*}}$, Tomoyuki Matsuda, RPT, $\mathrm{PhD}^{1)}$, \\ Yoshiniko Fujita, OTR, $\mathrm{PhD}^{2)}$, Shuichi Wakayama, OTR, $\mathrm{PhD}^{2)}$, \\ TAKESHI SASAKI, OTR, $\mathrm{MS}^{2)}$, KAZUSHI HotTA, OTR, $\mathrm{PhD}^{2)}$ \\ 1) Department of Physical Therapy, Ibaraki Prefectural University of Health Science: 4669-2 \\ Ami-machi, Inashiki-gun, Ibaraki 300-0394 Japan \\ 2) Department of Occupational Therapy, Ibaraki Prefectural University of Health Science, Japan
}

\begin{abstract}
Purpose] The coronavirus disease (COVID-19) pandemic has caused sudden lifestyle changes. This study aimed to determine the limitations in activity and the influences of remote exercise training on communitydwelling older adults during a state of emergency in Japan. [Participants and Methods] In May 2020, during the COVID-19 state of emergency, we carried out a mail survey of community-dwelling older adults who had previously participated in a disability prevention program in Ami town, Ibaraki, Japan. The mail included a brochure on exercises and a DVD. The attached exercise program was comprised of 10 different exercises, which could be conducted in approximately 30 minutes. [Results] Of the 191 older adults, 73 responded to this survey (38.2\%), of which $42(58.5 \%)$ participants had decreased outdoor exercise activity, and $50(68.5 \%)$ decreased the amount of time spent on physical activities during the COVID-19 state of emergency. There were significant reductions (19.2-22.5\%) in the perceived exercise load for each posture after two weeks of remote exercise training with DVD ( $\mathrm{n}=26)$. [Conclusion] Our results suggested that the remote exercise training with the brochure and DVD may be effective. Since this study involved a small number of participants, future studies should involve larger populations.

Key words: COVID-19, Remote training, Older adults
\end{abstract}

(This article was submitted Jun. 24, 2021, and was accepted Aug. 2, 2021)

\section{INTRODUCTION}

Maintaining physical activity is important for preventing frailty in older adults ${ }^{1)}$. The World Health Organization (WHO) declared coronavirus disease (COVID-19) as a global pandemic in March 20202). The Japanese government declared the first state of emergency from 7 April to 25 May 20203), closed schools and recreational and commercial facilities, and demanded that citizens stay at home as much as possible. Unlike lockdowns in other counties, restrictions in Japan were not enforceable ${ }^{4}$. It is important to reduce contact with others and stay at home to prevent infection. However, in the case of older people, this results in a reduction in their levels of physical activity, leading to an increased likelihood of falling, fractures, and nursing care needs ${ }^{5}$. Thus, it is important to find a balance between preventing infection and maintaining physical activity ${ }^{6}$.

The request to stay at home during the state of emergency caused concern for older adults due to fewer opportunities to go out or engage in physical activity. As it was not possible to instruct them in a group setting, we developed 10 different exercises that could be carried out at home using an instructional brochure and a DVD familiar to older adults, rather than the

*Corresponding author. Kazuhiro Miyata (E-mail: miyatak@ipu.ac.jp)

(Supplementary material: refer to PMC https://www.ncbi.nlm.nih.gov/pmc/journals/2193/)

(C2021 The Society of Physical Therapy Science. Published by IPEC Inc.

(c) (1) $\odot$ This is an open-access article distributed under the terms of the Creative Commons Attribution Non-Commercial No DerivacC. 
least mobile health technology. The purpose of this study was to reveal the status of activity limitation and the influences of remote exercise training on community-dwelling older adults during a national state of emergency.

\section{PARTICIPANTS AND METHODS}

This cross-sectional study was conducted in Ami Town, Ibaraki, Japan, and included 191 older adults who participated in a disability prevention program for older adults held by the university and Ami town from May 2015 to March 2020. The participants were older adults aged $\geq 65$ years who did not require long-term care; those with a history of dementia or neurological disorders were excluded. The disability prevention program was a class in which the participants learned about health, exercise, pain, diet, dementia, etc. a total of 10 times over approximately 3 months. We conducted a mail survey, and the questionnaires and written informed consent were returned by post. The present study was conducted in accordance with the guidelines proposed by the Declaration of Helsinki, and the study protocol was reviewed and approved by the Ethics Committee of the Ibaraki Prefectural University of Health Sciences (No. 962).

A selective questionnaire, a brochure of exercises, and a DVD were mailed to eligible participants. The survey was carried out in May 2020 after obtaining approval to survey Ami town, Ibaraki. After the questionnaire arrived, we instructed the participants to watch the brochure and DVD, complete two weeks of exercise, and then return the questionnaire. We investigated the personal characteristics (i.e., age and gender) and participants' perceived decline in physical activity. Participants were asked to respond on a five-point Likert scale (1="decreased" to 5="increased") to the following questions: (i) "Has there been any change in the opportunities for outdoor exercises, such as walking, after the declaration of the state of emergency?"; and (ii) "Has there been any change in the amount of time you spend exercising after the declaration of the state of emergency?"

The exercise program shown in the brochure and DVD comprised 10 different exercises, including maintaining good posture, leg exercises in the sitting position, leg exercises in the upright position, and arm exercises, which could be conducted in approximately $30 \mathrm{~min}$ (see Supplementary material) ${ }^{7}$. These exercises consist of a brochure that even older adults has used and a DVD that allows them to exercise together while viewing the monitor. Each exercise consisted of one set of 10 repetitions performed three times per day and was recorded on a checklist. Participants were asked to respond to the Visual Analog Scale (VAS) for the subjective degree of exercise load while exercising at the start and two weeks after the exercise. "Exercise load" was defined as hard when each exercise was performed 10 times.

Participants' characteristics and answers to the selective questionnaire were described using mean SD and count \%, as appropriate. To investigate the degree of improvement in exercise load, the VAS was compared using Student's t-test for each exercise of the lower and upper extremities at the start and after two weeks of remote exercise. Effect size $r$ was calculated to understand the magnitude of the difference. For subgroup analysis according to the two age categories, differences between young-old adults (age $<75$ years) and old-old adults (age $\geq 75$ years) were determined using Fisher's exact test and Student's t-test, as appropriate. We analysed the data using SPSS version 26.0, for Windows (IBM Corp., Armonk, NY, USA). A p-value less than 0.05 was considered statistically significant for all analysis.

\section{RESULTS}

Seventy-three residents responded to the survey (response rate: 38.2\%) (Fig. 1). The mean age of the respondents was 75.3 \pm 5.5 years, and 56 were female (76.7\%). Fifty-eight percent reported a decrease in the opportunities for outdoor exercise (decreased, 27.4\%; slightly decreased, 30.1\%), while 68.5\% reported a decrease in the amount of time spent participating in physical activities after the declaration of a state of emergency (decreased, 21.9\%; slightly decreased, 46.6\%) (Table 1). In the subgroup analysis, there was no difference in age $(\mathrm{p}>0.05)$.

There were significant reductions (19.2-22.5\%) in the perceived load of exercise in each posture after two weeks of remote exercise training $(\mathrm{p}<0.05$; Table 2$)$. All participants who responded to the exercise load performed at least one set and 10 different exercises every day. Subgroup analyses by age showed a significant reduction in the perceived load of exercise in young-old adults (age $<75$ years), except for upper extremity exercises. There was a significant reduction in the perceived load of all exercises in old-old adults (age $\geq 75$ years).

\section{DISCUSSION}

The present study revealed the status of activity limitations and the influences of remote exercise training on communitydwelling older adults during the state of emergency caused by the COVID-19 pandemic. Approximately half and two-thirds of community-dwelling older adults perceived declining opportunities for outdoor exercise and the amount of time spent participating in physical activities, respectively. In addition, for community-dwelling older adults, performing two weeks of remote exercise training reduced their perceived load of exercise to a certain degree during the state of emergency.

It is serious problem that $68.5 \%$ of the older adults perceived a decrease in physical activity. The COVID-19 pandemic has reduced physical activity among both adults and older adults in locked down countries ${ }^{8,9}$. In Japan, people requested a stayat-home order rather than a lockdown, and it was reported that physical activity declined compared to before the COVID-19 pandemic $^{10,11)}$. These results suggest that the physical activity of the older adults (including those with diseases) similarly 


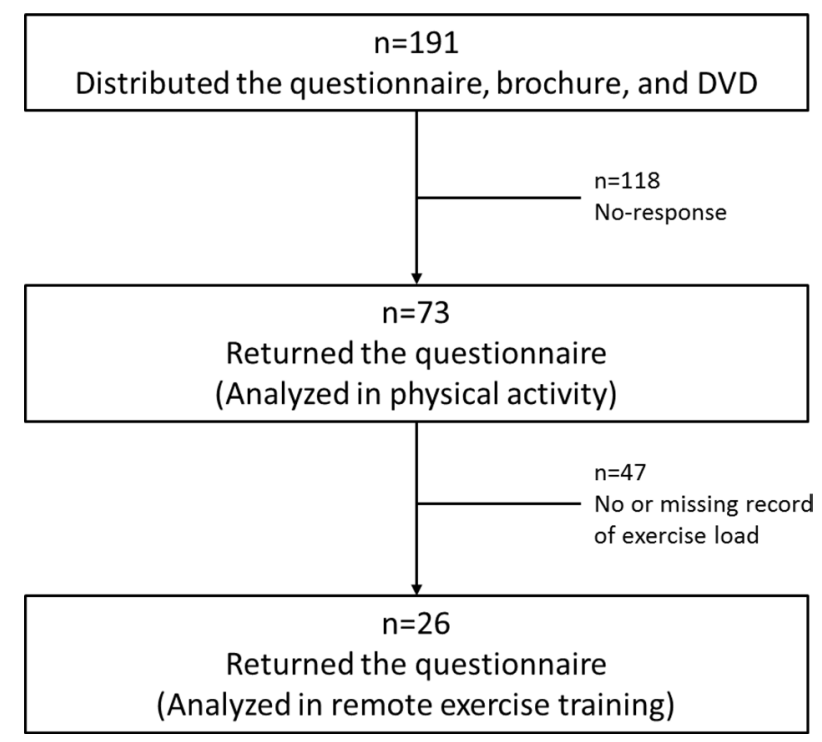

Fig. 1. The flowchart showing the study participants for analysis.

Table 1. Frequency of outdoor exercise and exercise time during a state of emergency $(n=73)$

\begin{tabular}{|c|c|c|c|c|c|c|c|c|c|c|c|}
\hline \multirow[b]{2}{*}{$\begin{array}{l}\text { Age strata } \\
\text { (years) }\end{array}$} & \multirow[b]{2}{*}{$\mathrm{n}$} & \multicolumn{5}{|c|}{ Q1. Outdoor exercise } & \multicolumn{5}{|c|}{ Q2. Exercise time } \\
\hline & & Decrease & $\begin{array}{l}\text { Slightly } \\
\text { decrease }\end{array}$ & No change & $\begin{array}{l}\text { Slightly } \\
\text { increase }\end{array}$ & Increase & Decrease & $\begin{array}{l}\text { Slightly } \\
\text { decrease }\end{array}$ & No change & $\begin{array}{l}\text { Slightly } \\
\text { increase }\end{array}$ & Increase \\
\hline $60-74$ & 31 & $6(19.4)$ & $11(35.5)$ & 7 (22.6) & $6(19.4)$ & & $5(16.1)$ & $12(38.7)$ & $11(35.4)$ & $2(6.5)$ & $1(0.7)$ \\
\hline $75 \geq$ & 42 & $14(33.3)$ & $11(26.2)$ & $13(31.0)$ & $4(9.5)$ & $0(0)$ & $11(26.2)$ & $22(52.4)$ & $7(16.7)$ & $2(4.8)$ & $0(0)$ \\
\hline Total & 73 & $20(27.4)$ & $22(30.1)$ & $20(27.4)$ & $10(13.7)$ & $1(0.1)$ & $16(21.9)$ & $34(46.6)$ & $18(24.7)$ & $4(5.4)$ & $1(0.1)$ \\
\hline
\end{tabular}

Q1. Has there been any change in opportunities for outdoor exercises, such as walking, after the declaration of the state of emergency? Q2. Has there been any change in the amount of time you spend exercising after the state of emergency?

Values are shown as frequency $(\%)$.

Table 2. Degree of improvement in exercise load by VAS after two weeks of remote exercise training $(\mathrm{n}=26)$

\begin{tabular}{lcccc}
\hline & Baseline & After two weeks & p-value & Effect size \\
\hline Lower extremities in sitting & $7.13(2.4)$ & $5.68(2.4)$ & $<0.001$ & 0.82 \\
Lower extremities in sitting & $6.67(2.1)$ & $5.30(2.4)$ & $<0.001$ & 0.74 \\
Upper extremities & $6.35(3.3)$ & $5.00(2.5)$ & 0.016 & 0.47 \\
\hline
\end{tabular}

VAS: visual analog scale.

decreased in different regions of Japan. In healthy or frail older adults, muscular weakness is decreased by physical activity ranging from low-intensity walking to more vigorous sports and resistance exercises ${ }^{12)}$. However, during the COVID-19 pandemic, it is difficult to increase one's physical activity using conventional approaches (i.e., hobbies, exercises, salons) while maintaining social distancing. New interventions, such as mobile technology and web-based services ${ }^{13-16)}$, are being attempted to maintain physical activity levels. We should increase the physical activity levels of community-dwelling older adults using a method that also considers infection control, and here we encouraged remote exercising using a simple method (brochure and DVD).

Our study revealed that remote exercise training for community-dwelling older adults reduced their perceived load of exercise to a certain degree during the state of emergency. Few respondents answered, but all continued to exercise daily. There are several types of remote exercises, and a review reported that using mobile health technology is effective for older adults ${ }^{17)}$. However, previous studies targeted individuals over 50 years of age, a different generation from the present study's target population, and their adaptation to mobile technology tends to occur slowly. Therefore, considering the feasibility and acceptance of older adults, we used a brochure and DVD for the remote exercise. These results suggest that this approach is effective and feasible for encouraging remote exercising in situations in which social distancing is necessary.

Although the present findings provide additional knowledge about the influences of physical activity and remote exercises 
in older people during the COVID-19 state of emergency, several limitations should be noted. First, the sample in this study were not randomly selected. The participants might have been highly motivated to improve their health and exercise because they had previously participated in a disability prevention program. For this reason, the generalization of the results requires caution. Second, the response rate was relatively low (38.2\%). In particular, a bias may exist in the survey as only 26 participants continued to exercise regularly, and only those who had positive effects responded to it. Third, we had to use an easy questionnaire and could not quantitatively measure physical activity and muscle strength. Finally, this was a cross-sectional survey of specific areas during a state of emergency that identified no changes over time. The COVID-19 pandemic is unprecedented worldwide and changing daily. In these socially chaotic situations, self-reported responses may vary depending on when and where data are collected.

In conclusion, approximately half and two-thirds of community-dwelling older adults examined here perceived declining opportunities for outdoor exercise and less amount of time spent participating in physical activities, respectively, during the state of emergency caused by the COVID-19 pandemic. Furthermore, this study demonstrated that the older adults who exercised while watching DVDs had reduced perceived load of exercise. Even in circumstances where it is difficult to gather and conduct activities while maintaining social distancing, it is suggested that instructing people to exercise at home using the brochure and DVD in the form of remote engagement may be beneficial.

\section{Conflict of interest}

The authors have no conflicts of interest to declare.

\section{ACKNOWLEDGEMENTS}

We are grateful to undergraduate students in our laboratory, the Department of Occupational Therapy or Physical Therapy at the Ibaraki Prefectural University of Health Science for appearing in the DVD, and Mrs. Shiori Tani, an occupational therapist, for creating the brochure.

\section{REFERENCES}

1) Fried LP, Tangen CM, Walston J, et al. Cardiovascular Health Study Collaborative Research Group: Frailty in older adults: evidence for a phenotype. J Gerontol A Biol Sci Med Sci, 2001, 56: M146-M156. [Medline] [CrossRef]

2) World Health Organization: WHO Director-General's opening remarks at the media briefing on COVID-19-11 March 2020. https://www.who.int/directorgeneral/speeches/detail/who-director-general-s-opening-remarks-at-the-media-briefing-on-covid-19---11-march-2020 (Accessed Jun. 7, 2021)

3) Prime Minister of Japan and His Cabinet: [COVID-19] Press Conference by the Prime Minister Regarding the Declaration of a State of Emergency-April 7, 2020. https://japan.kantei.go.jp/98_abe/statement/202004/00001.html (Accessed Jun. 7, 2021)

4) Watanabe T, Yabu T: Japan's voluntary lockdown: further evidence based on age-specific mobile location data. Jpn Econ Rev Oxf, 2021, 46: 1-38. [Medline]

5) Heiland EG, Welmer AK, Wang R, et al.: Cardiovascular risk factors and the risk of disability in older adults: variation by age and functional status. J Am Med Dir Assoc, 2019, 20: 208-212. e3. [Medline] [CrossRef]

6) Lim WS, Liang CK, Assantachai P, et al.: COVID-19 and older people in Asia: Asian Working Group for Sarcopenia calls to actions. Geriatr Gerontol Int, 2020, 20: 547-558. [Medline] [CrossRef]

7) Ibaraki Prefectural University of Health Sciences: Introduction to the IPUHS Exercise. https://www.ipu.ac.jp/introduction-ipuhs/ (Accessed Jun. 7, 2021)

8) Pérez LM, Castellano-Tejedor C, Cesari M, et al.: Depressive symptoms, fatigue and social relationships influenced physical activity in frail older communitydwellers during the Spanish lockdown due to the COVID-19 pandemic. Int J Environ Res Public Health, 2021, 18: 808. [Medline] [CrossRef]

9) Buoite Stella A, AjČeviĆ M, Furlanis G, et al.: Smart technology for physical activity and health assessment during COVID-19 lockdown. J Sports Med Phys Fitness, 2021, 61: 452-460. [Medline] [CrossRef]

10) Yamada M, Kimura Y, Ishiyama D, et al.: Effect of the COVID-19 epidemic on physical activity in community-dwelling older adults in Japan: a cross-sectional online survey. J Nutr Health Aging, 2020, 24: 948-950. [Medline] [CrossRef]

11) Suzuki Y, Maeda N, Hirado D, et al.: Physical activity changes and its risk factors among community-dwelling Japanese older adults during the COVID-19 epidemic: associations with subjective well-being and health-related ouality of life. Int J Environ Res Public Health, 2020, 17: 6591. [Medline] [CrossRef]

12) McPhee JS, French DP, Jackson D, et al.: Physical activity in older age: perspectives for healthy ageing and frailty. Biogerontology, 2016, 17: 567-580. [Medline] [CrossRef]

13) Banskota S, Healy M, Goldberg EM: 15 smartphone apps for older adults to use while in isolation during the COVID-19 Pandemic. West J Emerg Med, 2020, 21: 514-525. [Medline] [CrossRef]

14) Srivastav AK, Khadayat S, Samuel AJ: Mobile-based health apps to promote physical activity during COVID-19 lockdowns. J Rehabil Med Clin Commun, 2021, 4: 1000051. [Medline]

15) Middleton A, Simpson KN, Bettger JP, et al.: COVID-19 pandemic and beyond: considerations and costs of telehealth exercise programs for older adults with functional impairments living at home-lessons learned from a pilot case study. Phys Ther, 2020, 100: 1278-1288. [Medline] [CrossRef]

16) Quinn L, Macpherson C, Long K, et al.: Promoting physical activity via telehealth in people with Parkinson disease: the path forward after the COVID-19 pandemic? Phys Ther, 2020, 100: 1730-1736. [Medline] [CrossRef]

17) McGarrigle L, Todd C: Promotion of physical activity in older people using eHealth and eHealth technologies: rapid review of reviews. J Med Internet Res, 2020, 22: e22201. [Medline] [CrossRef] 